\title{
A multimedia oral health promoting project in primary schools in central Italy
}

Iole Vozza, DDS, PhD

Fabrizio Guerra, MD, DDS

Massimiliano Marchionne, BSDH

Ercole Bove, MD, DDS

Denise Corridore, DDS

Livia Ottolenghi, DDS

Department of Oral and Maxillo Facial Sciences, "Sapienza" University of Rome, Italy

Corresponding author:

Iole Vozza

Department of Oral and Maxillo Facial Sciences, "Sapienza" University of Rome

Via Caserta 6

00161 Rome, Italy

E-mail: iole.vozza@uniroma1.it

\section{Summary}

Aim. The purpose of the study Project was to test the effectiveness of a multimedia game designed in order to attract the attention of primary school children to oral health basic concepts and use the instrument to assess students' knowledge.

Materials and methods. An originally designed multimedia game on oral health was administered in the computer class rooms, before (T0) and after (T1) an educational stage, to third (8-9 years) and fifth graders (10-11 years) of primary schools in urban and rural areas of two provinces of medium-small cities in Center Italy (Terni and Latina). Considered variables were: age, gender, school time schedule (only antemeridian, extended schedule). The statistical test used was the nonparametric Wilcox on signed-rank test.

Results. Response rate was $90.6 \%$ (due to absence on the due date). 1,300 students were involved. Overall, the average of the correct answers was $40.7 \%$ before oral health lessons and $59.2 \%$ after. An improving trend of correct answers was recorded from T0 to T1, significantly ( $p$ $<0.05)$ among: fifth graders $(+17.5 \%)$, extended school time schedulers $(+18.1 \%)$ and females $(+18.9 \%)$. The results, however, show poor global oral health knowledge, being total percentage of correct answers below $60 \%$.

Conclusions. The results stress the importance of the school environment as access to health promotion for all socio-economic classes. The multi- media educational approach has proved a valuable and updated tool to attract the attention of digital native children.

Key words: oral health, health promoting school, primary school.

\section{Introduction}

As children spend a considerable proportion of their lives in education, schools can play a significant role in promoting their oral health. Schools reach over 1 billion children worldwide and are recognized as useful settings for health promotion (1). Oral health messages can be reinforced during the school years, which are the most influential stages of children's lives. Health promoting schools (HPS) is increasingly adopted as an approach to guide supportive practices in promoting the development of healthy behaviors in the early years. Health promotion was codified by Ottawa Charter for Health Promotion in the First International Conference on Health Promotion, on 1986. The European Network of Health-Promoting Schools (ENHPS) started in 1992, followed by the establishment of the WHO Global School Health Initiative in 1995 (2). The Ottawa Charter for Health promotion was thereby transformed into practice. Encouraging children to adopt healthy lifestyle habits is a central objective, and health promotion at a community level, particularly through health promoting schools, may be an effective strategy. Thus, a Health Promoting School should aim to:

- Promote lifestyles conducive to good health

- Provide an environment supporting healthy lifestyles

- Give students and staff the ability to take action for a healthier community and healthier living conditions (3).

The influence of childhood experiences on health status through HPS is well documented and implemented worldwide (4-6). Different studies in Italy focused the importance of oral health promotion at school $(7$, $8)$; the Italian Ministry of Health published a volume about "Promotion and protection of health in children and adolescents: criteria of clinical, technological and structural appropriateness" in 2012 to promote oral health among children and adolescents (9) following the criteria of the Regional Office for Europe of the World Health Organization developed in the volume entitled "Gaining health" (10). Oral health education can be taught as a specific subject or as part of health promotion integrated approaches with active 
participation aiming to sustainable changes in healthrelated behavior. The purpose of this study was to test the effectiveness of a multimedia game designed in order to attract the attention of primary school children to oral health basic concepts and use the instrument to assess students' knowledge.

Multimedia approach has been chosen in order to encounter digital natives' interests and learning strategies.

\section{Materials and methods}

Third (8-9 years) and fifth graders (10-11 years) of elementary schools in two provinces of mediumsmall cities in Center Italy have been involved in the study. The schools were chosen including urban and rural areas of the two provinces. An originally designed multimedia game on oral health was administered in the computer class rooms, before (T0) and after (T1) an educational stage, to the pupils. The test was completely anonymous and there was no need of ethical approval. A written informed parental consent was collected before the first administration. The multimedia game consisted of five questions on issues referring to the Health Promoting Schools program. The study was divided into three separate phases. The first phase consisted in the administration of questions and data collection. The second phase was concentrated on oral health lessons in the selected schools. The lessons concerned basic knowledge of dental anatomy, methods of brushing and proper nutrition. The third and final phase provided for the re-administration of the game, and the subsequent data collection, in order to assess the learning level. The questions are reported in Table 1. The first question reflected, significantly, as well as the knowledge of the role of the dentist, the socio-cultural situation of the family and therefore the knowledge of primary oral prevention transmitted to children. The second question was about the right technique of brushing and the third question concerned caries and knowledge of secondary prevention. The fourth question inquired about the importance of fluoride. The fifth question focused on toothbrush and its use. Once completed the questions the multimedia program processed the answers and the monitor displayed a picture of a cartoon character who lost a couple of teeth for each wrong answer. The first pair of teeth on the left of the image was associated to the first question and so forth in a sequential manner (Fig. 1). The collected data were then statistically analyzed. Considered variables were: age, gender, school time schedule (antemeridian, extended). The statistical test used was the non-parametric Wilcox on signedrank test.

\section{Results}

The study included 1,300 third (8-9 years) and fifth graders (10-11 years) of 14 elementary schools in two provinces of medium-small cities in Center Italy (651 students of 6 schools in Terni and 649 students of 7 schools in Latina). The data are summarized in Table 2. Response rate was $90.6 \%$ (due to absence on the administration date). The results are described in Figures 2-4. On 1,300 tested students the average of the correct answers was $40.7 \%$ at T0 and $59.2 \%$ at T1. On the whole there was an improving trend of correct answers after the educational phase, signifi-

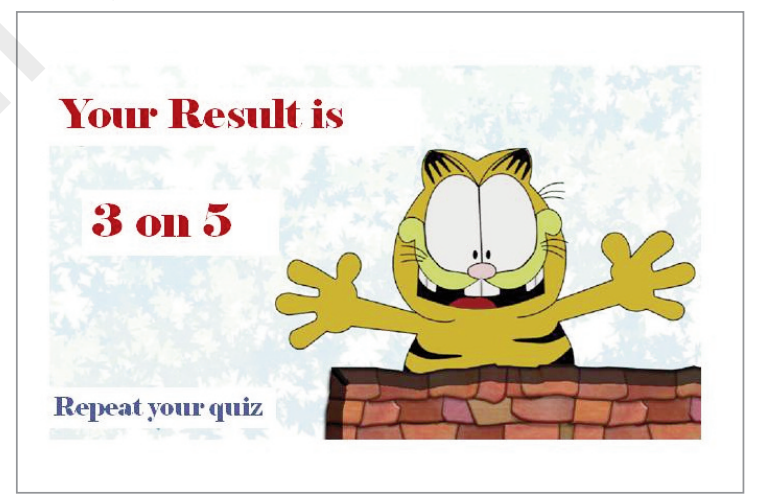

Figure 1. Results of the quiz by a cartoon.

Table 1. Multimedia questions about oral health.

\begin{tabular}{|c|c|c|c|c|}
\hline Question 1 & Question 2 & Question 3 & Question 4 & Question 5 \\
\hline $\begin{array}{l}\text { How often should } \\
\text { you visit the dentist? }\end{array}$ & $\begin{array}{l}\text { How do you use } \\
\text { your toothbrush? }\end{array}$ & $\begin{array}{l}\text { What happens if the } \\
\text { tooth has a cavity? }\end{array}$ & What is fluoride? & $\begin{array}{l}\text { How often should you } \\
\text { change your toothbrush? }\end{array}$ \\
\hline $\begin{array}{l}\text { A) Every } 2 \text { years } \\
\text { B) When you need } \\
\text { C) Every } 6 \text { months }\end{array}$ & $\begin{array}{l}\text { A) Fast horizontal } \\
\text { movements in order } \\
\text { to clean all teeth } \\
\text { B) Gentle circular and } \\
\text { short movements in } \\
\text { order to clean one } \\
\text { tooth at a time } \\
\text { C) Horizontal and } \\
\text { vertical movements } \\
\text { in order to clean } \\
\text { everything quickly }\end{array}$ & $\begin{array}{l}\text { A) Decay sooner or } \\
\text { later goes away by itself } \\
\text { B) It's possible to stop } \\
\text { small cavities and } \\
\text { save the tooth } \\
\text { C) Decay always } \\
\text { increases tooth size } \\
\text { and you can lose } \\
\text { your tooth }\end{array}$ & $\begin{array}{l}\text { A) It protects teeth } \\
\text { from decay } \\
\text { B) It cleans teeth } \\
\text { with the toothbrush } \\
\text { C) It freshens breath }\end{array}$ & $\begin{array}{l}\text { A) When bristles ruin } \\
\text { B) When it becomes } \\
\text { black } \\
\text { C) Once a year }\end{array}$ \\
\hline
\end{tabular}


cantly $(p<0.05)$ in: fifth graders $(+17.5 \%)$, extended school time schedulers $(+18.1 \%)$ and females $(+18.9 \%)$. No significant differences were found among schools in urban and rural areas of the two provinces. The results, however, show poor overall oral health knowledge, being total percentage of correct answers below $60 \%$. These data are even more worrying, given the simplicity of the administered questions.

Table 2. Sample distribution by variables.

\begin{tabular}{llll}
\hline & Latina & Terni & Total \\
\hline Females & 297 & 311 & 608 \\
Males & 352 & 340 & 692 \\
$3^{\text {rd }}$ Grade & 298 & 304 & 602 \\
$5^{\text {th }}$ Grade & 351 & 347 & 698 \\
Antemeridian schedule & 77 & 92 & 169 \\
Extended schedule & 572 & 559 & 1131 \\
Total & $\mathbf{6 0 8}$ & $\mathbf{6 9 2}$ & $\mathbf{1 3 0 0}$ \\
\hline
\end{tabular}

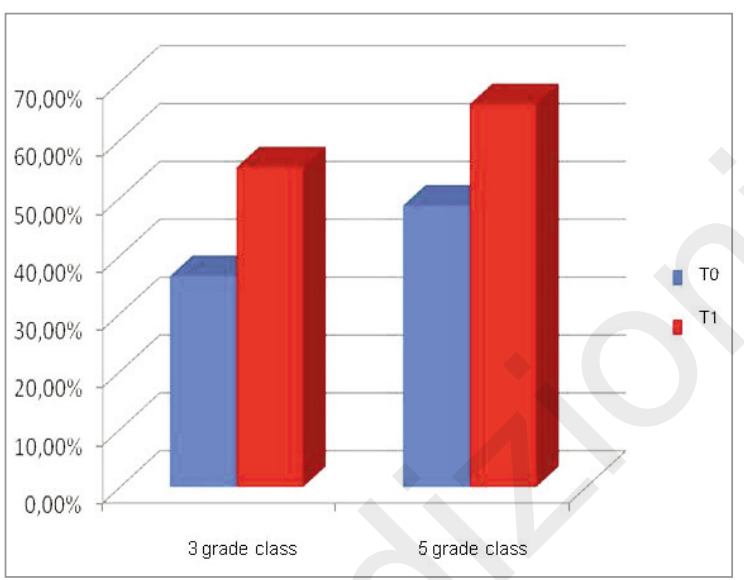

Figure 2. Improving trend of correct answers from T0 to T1 among fifth graders.

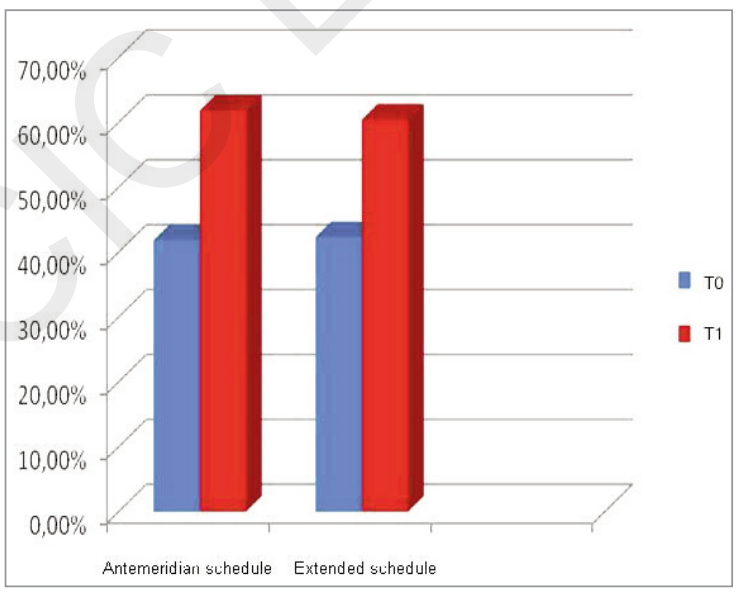

Figure 3. Improving trend of correct answers from T0 to T1 among extended school time schedulers.

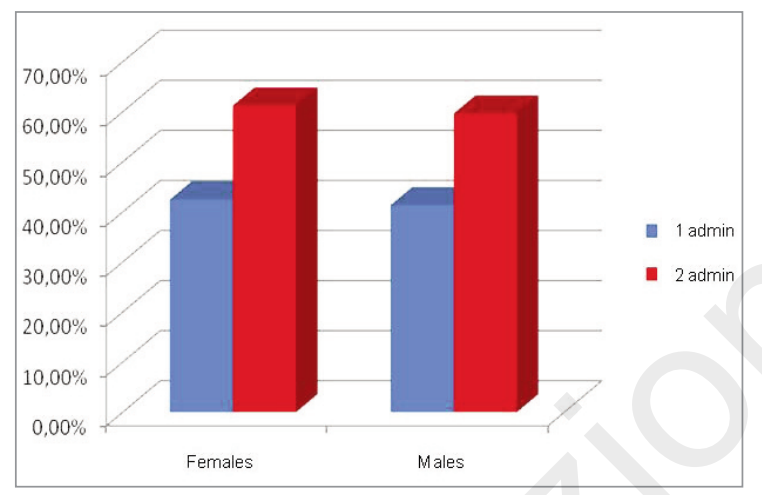

Figure 4. Improving trend of correct answers from T0 to T1 among females.

\section{Discussion}

Decay and gum disease are among the most diffused conditions in human populations, affecting over $80 \%$ of school children in some countries (11). Many oral health problems are preventable and their early onset reversible. However, in several countries a considerable number of children, their parents and teachers have poor access to oral health care and limited knowledge of oral health prevention. The problems are exacerbated by the consumption of sugary snacks and carbonated drinks which is high among children and adolescents (12-14). Encouraging children to adopt healthy lifestyle habits, and promoting oral health through Health Promoting Schools, may be an effective strategy. Many studies focused on the effect of oral health promoting schools in different countries (15-20). In Italy this is an ongoing process particularly followed through the project "Guadagnare salute" in collaboration with the Ministry of Health (21). Providing education on oral health in schools helps children to develop personal skills, provides knowledge about oral health and promotes positive attitudes and healthy behaviors. In this historical context, children show a continued interest to multimedia games. For this reason the quiz administered proved of great interest among students arousing curiosity and fun. From the analyzed results of this study it was found that 5 graders, as easily conceivable, showed greater knowledge in the field of oral health compared to 3 graders. A significant statistical difference was also found among males and females and among children who attended school with extended schedule time and those who attended antemeridian school time schedule. The study revealed an improvement of oral health and prevention knowledge although this result can still be considered inadequate, being total percentage of correct answers below $60 \%$. It's fundamental improving knowledge about fluoride and white spot avoiding the onset of carious cavity and subsequent treatment with invasive mechanical aids $(22,23)$. To build a comprehensive oral health preventive program, three elements are essential that are oral health education/instruction, primary and secondary prevention measures (24). The school plays a crucial role, 
raising awareness both for students as parents to support a prevention protocol for oral health. In this study school proved to be a suitable environment for testing the multimedia project. In addition, the informed consent required to parents for quiz administration of students, was able to promote parent knowledge and attitude towards oral health and prevention in order to affect their children oral health behavior and status as described in other studies $(25,26)$. Parents are considered as the key factors for developing children and shaping their healthy behaviors. However despite a growing body of research regarding the health-promoting schools (HPS), research on measuring of the HPS is limited and this could be the topic of future studies.

\section{Conclusions}

The school has proved an ideal environment for oral health promotion project, both for the amount of catchment area, and for efficiency and speed of child population screening. The results stress the importance of the school environment as where you can access to health services for all socio-economic classes. Creating a game from the multimedia features, has proved a valuable tool to attract the attention of digital native children.

\section{References}

1. Kwan SY, Petersen PE, Pine CM, Borutta A. Health-promoting schools: an opportunity for oral health promotion. Bull World Health Organ. 2005 Sep;83(9):677-85.

2. Honkala S. World Health Organization approaches for surveys of health behaviour among schoolchildren and for healthpromoting schools. Med Princ Pract. 2014;23 Suppl 1:24-31.

3. The status of school health. Report of the School Health Working Group and the WHO Expert Committee on Comprehensive School Health Education and Promotion. Geneva: World Health Organization. 1996.

4. Singh S. Evidence in oral health promotion-implications for oral health planning. Am J Public Health. 2012 Sep;102(9):e15-8.

5. Jürgensen N, Petersen PE. Promoting oral health of children through schools-results from a WHO global survey 2012. Community Dent Health. 2013 Dec;30(4):204-18. PubMed PMID: 24575523.

6. Langford R, Bonell CP, Jones HE, Pouliou T, Murphy SM, Waters E, Komro KA, Gibbs LF, Magnus D, Campbell R. The WHO Health Promoting School framework for improving the health and well-being of students and their academic achievement. Cochrane Database Syst Rev. 2014 Apr 16;4:CD008958.

7. Panetta F, Dall'Oca S, Nofroni I, Quaranta A, Polimeni A, Ottolenghi L. Early childhood caries. Oral health survey in kindergartens of the 19th district in Rome. Minerva Stomatol. 2004 Nov-Dec;53(11-12):669-78.

8. Campus G, Senna A, Cagetti MG, Maida C, Strohmenger L. Caries experience and status in school-age children re- siding in four North Italian communities. Oral Health Prev Dent. 2005;3(1):33-8.

9. Ministry of Health. Promotion and protection of health in children and adolescents: criteria of clinical, technological and structural appropriateness. 2012. Available from: http://www.quadernidellasalute.it/download/download/16luglio-agosto-2012-quaderno.pdf

10. Regional Office for Europe of the World Health Organization. Gaining health. 2006. Available from: http://www.euro. who.int/_data/assets/pdf_file/0008/76526/E89306.pdf

11. Global Oral Health Data Bank. Geneva: World Health Organization; 2004.

12. Pizzo G, Piscopo MR, Matranga D, Luparello M, Pizzo I, Giuliana G. Prevalence and socio-behavioral determinants of dental caries in Sicilian schoolchildren. Med Sci Monit. 2010 Oct;16(10):PH83-9.

13. Zaborskis A, Milciuviene S, Narbutaite J, Bendoraitiene E, Kavaliauskiene A. Caries experience and oral health behaviour among 11-13-year-olds: an ecological study of data from 27 European countries, Israel, Canada and USA. Community Dent Health. 2010 Jun;27(2):102-8.

14. Krisdapong $S$, Prasertsom $P$, Rattanarangsima K, Sheiham A. Sociodemographic differences in oral health-related quality of life related to dental caries in thai school children. Community Dent Health. 2013 Jun;30(2):112-8.

15. Lisboa CM, de Paula JS, Ambrosano GM, Pereira AC, Meneghim Mde C, Cortellazzi KL, Vazquez FL, Mialhe FL. Socioeconomic and family influences on dental treatment needs among Brazilian underprivileged schoolchildren participating in a dental health program. BMC Oral Health. 2013 Oct 19;13:56.

16. Iglesias Guerra JA, Fernández Calvo MT, Barrón Sinde J, Bartolomé Lozano M. Evolution of knowledge and oral hygiene habits in primary schoolchildren. Gac Sanit. 2013 JulAug;27(4):362-4.

17. Takeuchi R, Kawamura K, Kawamura S, Endoh M, Tomiki $\mathrm{S}$, Taguchi C, Kobayashi S. Effect of school-based fluoride mouth-rinsing on dental caries incidence among schoolchildren in the Kingdom of Tonga. J Oral Sci. 2012;54(4):343-7.

18. Matulaitiene ZK, Zemaitiene M, Zemgulyte S, Milciuviene S. Changes in dental caries and oral hygiene among 7-8 yearold schoolchildren in different regions of Lithuania 1983-2009. Stomatologia. 2012;14(2):53-9.

19. Yekaninejad MS, Eshraghian MR, Nourijelyani K, Mohammad K, Foroushani AR, Zayeri F, Pakpour AH, Moscowchi A, Tarashi M. Effect of a school-based oral health-education program on Iranian children: results from a group randomized trial. Eur J Oral Sci. 2012 Oct;120(5):429-37.

20. Pike J, loannou S. Evaluating school-community health in Cyprus. Health Promot Int. 2013 Aug 8. [Epub ahead of print].

21. Available from: http://www.guadagnaresalute.it/

22. Brostek AM, Walsh LJ. Minimal intervention dentistry in general practice. Oral Health Dent Manag. 2014 Jun;13(2):285-94.

23. Maguire A. ADA clinical recommendations on topical fluoride for caries prevention. Evid Based Dent. 2014 Jun;15(2):38-9.

24. Lam A. Elements in oral health programs. N Y State Dent J. 2014 Mar;80(2):26-30.

25. Bozorgmehr E, Hajizamani A, Malek Mohammadi T. Oral health behavior of parents as a predictor of oral health status of their children. ISRN Dent. 2013 May 8;2013:741783.

26. Garbin C, Garbin A, Dos Santos K, Lima D. Oral health education in schools: promoting health agents. Int J Dent Hyg. 2009 Aug;7(3):212-6. 